\title{
Are coping styles consistent in the teleost fish Sparus aurata through sexual maturation and sex reversal?
}

\author{
Castanheira Maria Filipa ${ }^{1,{ }^{*}}$, Martínez Páramo Sonia ${ }^{1}$, Figueiredo F. ${ }^{1,2}$, Cerqueira Marco ${ }^{1}$, Millot \\ Sandie $^{3}$, Oliveira Catarina C. V. ${ }^{1}$, Martins Catarina I. M. ${ }^{1,4}$, Conceição Luís E. C. ${ }^{1,5}$
}

${ }^{1}$ Centro de Ciências do Mar (CCMAR), Universidade do Algarve, Campus de Gambelas, 8005-139, Faro, Portugal

2 Troms Kråkebolle AS, Ullstindveien 674, 9019, Krokelvdalen, Norway

${ }^{3}$ Laboratoire Ressources Halieutiques, Ifremer, Place Gaby Coll, BP 7, 17137, L'Houmeau, France

${ }^{4}$ Marine Harvest ASA, Bergen, Norway

${ }^{5}$ SPAROS Lda, Área Empresarial de Marim, Lote C, 8700-221, Olhão, Portugal

* Corresponding author : Maria Filipa Castanheira, email address : maria.filipa.castanheira@gmail.com

\begin{abstract}
:
Individual differences in behaviour and physiological responses to stress are associated with evolutionary adaptive variation and thus raw material for evolution. In farmed animals, the interest in consistent trait associations, i.e. coping styles, has increased dramatically over the last years. However, one of limitations of the available knowledge, regarding the temporal consistency, is that it refers always to short-term consistency (usually few weeks). The present study used an escape response during a net restraining test, previously shown to be an indicative of coping styles in seabream, to investigate longterm consistency of coping styles both over time and during different life history stages. Results showed both short-term (14 days) consistency and long-term (8 months) consistency of escape response. However, we did not found consistency in the same behaviour after sexual maturation when the restraining test was repeated 16, 22 and 23 months after the first test was performed. In conclusion, this study showed consistent behaviour traits in seabream when juveniles, and a loss of this behavioural traits when adults. Therefore, these results underline that adding a life story approach to data interpretation as an essential step forward towards coping styles foreground. Furthermore, a fine-tuning of aquaculture rearing strategies to adapt to different coping strategies may need to be adjusted differently at early stages of development and adults to improve the welfare of farmed fish.
\end{abstract}

Keywords : Individual variation, Personality, Farm animals, Production, Sperm quality, Stress response 


\section{Introduction}

The study of consistent trait associations in behaviour and physiological responses to challenges (i.e. animal personality or coping style) are associated with adaptive variation and thus, become a raw material for evolution in a wide range of biological disciplines (Francis 1990; Gosling 2001; Koolhaas et al. 1999; Korte et al. 2005; Réale et al. 2007; Sih et al. 2004). An understanding of this inter-individual variation is essential to improve our knowledge of the adaptive value of behaviour and physiological traits (Koolhaas et al., 1999). In the scientific literature, these consistent individual differences are alternatively referred to as personality (Gosling, 2001), temperament (Réale et al., 2007), behavioural syndromes (Sih et al., 2004) or coping styles (Koolhaas et al., 1999). The previous terminology stand for different phenomena: personality defines consistency of at last one single behavioural trait, but can also include correlations between multiple traits (Gosling, 2001); temperament describes the idea that individual behavioural differences are repeatable situations and should be studied within an evolutionary ecology framework (Réale et al., 2007); behavioural syndromes demark a set of correlated behavioural traits (Sih et al., 2004) and coping styles defines a set of behavioural patterns correlated with consistent physiological traits (Koolhaas et al., 1999).While, despite the diversity of terminology and designated definitions (Francis 1990; Gosling 2001; Koolhaas et al. 1999; Sih et al. 2004), there seems to be a consensus that individual differences in certain 
traits biologically meaningful and are consistent and predictive of other behavioural patterns or physiological responses shown in another context.

Several studies in fish have provided early documentation on individual consistency (Castanheira et al. 2013a,b; Coppens et al. 2010; Koolhaas et al. 1999; Martins et al. 2012; Millot et al. 2014; Øverli et al. 2004, 2007; Ruiz-Gomez et al. 2011; Schjolden and Winberg 2007) that reflects distinct behavioural and physiological patterns usually categorized in two contrasting personality types, proactive (active coping or bold or 'fight-flight') and reactive (passive coping or shy or 'non-aggressive') (Koolhaas et al. 1999; Øverli et al. 2007). Behaviourally, proactive individuals are characterised by active avoidance (Brelin et al. 2005; Castanheira et al. 2013a; Laursen et al. 2011; Martins et al. 2011; Silva et al. 2010), low flexibility (Chapman et al. 2010; Ruiz-Gomez et al. 2011), high levels of aggression (Castanheira et al. 2013b; Øverli et al. 2004, 2005), territorial control (Øverli et al. 2004, 2005), and other behavioural responses that suggest active efforts to counteract a negative stimulus, this pattern being the opposite for reactive individuals (reviewed in Castanheira et al. 2016; Koolhaas et al. 1999; Øverli et al. 2007)). Physiologically, proactive individuals exhibit typical physiological and neuroendocrine characteristics such as lower hypothalamus-pituitaryinterrenal (HPI) activity and lower HPI reactivityas compared to reactive individuals (reviewed in Castanheira et al. 2016; Koolhaas et al. 1999; Øverli et al. 2007).Nowadays, stress-coping styles are clearly identified in fish and have contributed to the understanding of individual variation in the capacity to cope with stressful events (i.e. conditions that are well tolerated by some individuals may be detrimental to others) (Huntingford and Adams 2005).

In farmed fish, the interest in consistent trait associations, i.e. coping styles, has increased dramatically over the last years because many studies have demonstrated links to performance traits ( $\varnothing$ verli et al. 2007; Martins et al. 2011), health and diseases resistance (Fevolden et al. 1992, 1993; MacKenzie et al. 2009; Kittilsen et al. 2012) and welfare (Huntingford and Adams 2005; Huntingford et al. 2006). For example, in common carp 
(Huntingford et al. 2010) and seabass (Millot et al. 2009) the feed competition was shown to be related with distinct risk-taking behaviour. Data from Martins et al. (2011) shown that proactive tilapias were more feed efficient and has a faster recovery of feed intake after transfer. Another important implication of coping styles in farmed fish is the distinct disease resistance between coping styles. MacKenzie et al. 2009 showed that proactive and reactive common carp responded differently to inflammatory challenge with bacterial pathogens.

A failure to accommodate the coping styles of fish under farming conditions can lead to problems linked with production (e.g. aggression, growth and disease resistance).

Thus, a consensus is emerging that increased understanding of the consequences of stresscoping styles in aquaculture is important to safeguard a sustainable development of this industry and increase the production output.

However, there is still a long way to completely understand the coping styles thematic in order to improve the management and welfare of farmed fish.

One of the major gaps in the literature concerning the characterisation of coping styles in fish, is related with the temporal consistency, once published work so far refers to short-term (usually a few weeks) consistency (Basic et al. 2012; Castanheira et al. 2013a).

Although behavioural ecologists begun to consider potential links between life history tradeoffs, related with productivity (i.e. growth and/or fecundity) and personality traits in animals (Biro and Stamps. 2008). For instance, in rainbow trout Oncorhynchus mykiss, shy individuals consistently showed strong anti-predatory responses than bold individuals, both as juveniles and as adults stages (Biro et al. 2006, 2004). In Atlantic salmon Salmo salar, consistent differences in growth trajectories that appear at an early age were correlated with migration variation later in life (McCarthy 2000; Metcalfe et al. 1998). According the previous studies, a life-history approach of these individual differences is essential, to increase our knowledge on the adaptive value of coping styles in farming fish.In fact, Seebacher et al. (2015) proposed an integrative framework for underlying the physiological mechanisms and ultimate 
112 a mechanistic performance related with muscle contractile function and differences in 113 voluntary speed could explain behavioural differences between individuals within populations.

114 In agreement with the previous study, in seabream, one of the traits that have been shown to 115 be consistent over time and across context is the escape response under a restraining test 116 (Castanheira et al. 2013a). In addition, escape performance has ecological significance 117 (predator-prey-interaction), physiological implications (anaerobic recovery capacity of white muscle) and can be considered as a parallel to the forced swimming test, which is widely used in rodents for biomedical studies to coping styles screening. Moreover, the escape performance is very representative of conditions that the fish have to deal in practical aquaculture conditions (e.g. grading, vaccination, transport). Thus, we used the escape response in a net to validate the temporal consistency over time in seabream. Moreover,very little is known about the influence of maturation or sex change on the coping strategies of fish species that undergo sex inversion such as the protandrous hermaphrodite teleost, seabream Sparus aurata. In farming conditions, sex inversion usually occurs around the end of the second year (Brusléa-Sicard and Fourcault 1997) when males undergo sex reversal into females. In fish, it is well documented that gender has a factor influencing coping strategies (Øverli et al. 2006). Øverli et al. (2006) addressed changes in the locomotor response to an acute confinement stress between male and female rainbow trout (Oncorhynchus mykiss), with females decreasing and stopping to move faster than males. Sex inversion may have important consequences for differences that can be found in coping strategies between fish at early life stages of development and adults. In addition, stressful events (e.g. being chased by a net, being in a more crowded environment) are linked to a decrease in sperm motility and eggs fertilization (Schreck 2010). According to this we expected that proactive individuals are more successful breeders. In fish, few studies indicate that coping styles could be linked to sperm motility. Ibarra-Zatarain et al (2013) did 
137 not found a significant effect of coping styles in gamete quality in Senegalese sole (Solea

138 senegalensis). However, Clement et al $(2005 a, b)$ found that dominant African cichlid fish

139 (Astatotilapia burtoni) are more effective breeders. The lack of information and distinct results

140 found in sperm motility and coping styles, highlights the needs for further investigation in this

141 topic.

142 The objective of the current study was to investigate the consistency of coping styles over time

143 and during life history using the behavioural responses during a net restraining test and

144 cortisol responsiveness at distinct developmental stages. This approach made it possible to

145 assess the influence of maturation and sex inversion on coping strategies in gilthead seabream,

146 a fish species that undergoes sex inversion. We predicted that both age and life experience

147 would influence the individual behavioural consistency of coping styles thus, the individual

148 adaptation capacity may be different according life history. Therefore, a life history approach

149 of coping styles could represent a new key to enhance, fish welfare, improve disease

150 resistance and performance at distinct stages of fish development reflected in aquaculture 151 sustainability.

152

153

\section{Methods}

154

The experiment was conducted in accordance with the Guidelines of the European Union

Council (86/609/EU) and Portuguese legislation for the use of laboratory animals, and under a

"Group-1" license approved by the ethics committee from the Veterinary Medicines

Directorate, the Portuguese competent authority for the protection of animals, Ministry of 09/11/2009. 
164 The study was performed at the Ramalhete Research Station (CCMAR, Faro, Portugal). Fish

165 were acquired from a seabream breeder without selection programme based on behavioural profile (MARESA Mariscos de Esteros SA, Huelva, Spain). All individuals used were housed in fibreglass stock tanks (500L) under standard rearing conditions (Morales 1983) until the experiment start. Throughout all the experimental period (24 months) water parameters were daily analysed with an average water temperature of $19.5 \pm 2.1 \stackrel{\circ}{\circ}$, a salinity of $34.3 \pm 2.4 \%$ o dissolved oxygen concentration of $96.5 \pm 3.3 \%$, nitrites $\left(<0.1 \mathrm{mg} . \mathrm{L}^{-1}\right)$ and ammonia $\left(<0.1 \mathrm{mg} . \mathrm{L}^{-}\right.$ ${ }^{1}$ ) and a natural photoperiod was provided ( $\left.37^{\circ} 0^{\prime} 22.35^{\prime \prime} \mathrm{N} 7^{\circ} 58^{\prime} 3.35^{\prime \prime} \mathrm{W}\right)$. Fish were fed 0.5 to $2 \% \mathrm{BW} \mathrm{day}^{-1}$, by hand, twice per day (09:30 and 14:30), with a commercial diet (Aquagold 2, 3 and $5 \mathrm{~mm}$, Sorgal SA, Portugal) according to the body weight. The same diet and photoperiod were used through the experiment.

Fish were PIT-tagged (ID100 Implantable Transponder, Trovan ${ }^{\circledR}$, Netherlands; Dimensions: 2.12 x 11.5mm), two weeks before the start of the experimental procedures. PIT-tag was inserted through an injection device (ID100/Disponsable Implantable Transponder, $\operatorname{Trovan}^{\circledR}$, Netherlands), under the skin on the left side of the dorsal fin. All animals behaved normally after PIT-tagged (i.e. without changes in swimming speed, manoeuvre swimming complexity and feed intake).

\subsection{Experimental procedures}

\subsubsection{Coping styles screening} Individually tagged juvenile fish $(n=60,22.7 \pm 3.9$ g; mean $\pm S D$ ) were initial screening using a consecutive series of behavioural tests: (1) feeding recovery after transfer to a novel environment; (2) behaviour towards a novel object; (3) escape response and cortisol responsiveness in a restraining test, 4) avoidance response towards hypoxia conditions and 5) 
risk taking. Each test was repeated twice (run 1 and run 2) 14 days apart to assess short-term consistency of behavioural responses over time (for details see Castanheira et al. 2013).

190 Using previous results (Castanheira et al. 2013a,b), the escape behaviour during the restraining test was applied to validate if the coping styles found in this species are stable along life stages, i.e. long term consistency.Briefly, the net restraining test consists of holding each fish individually in an emerged net for one minute. While in the net the following variables were measured: i) latency to escape (time in seconds taken by each fish to show an escape attempt; escape attempt was defined as an elevation of the body from the net; ii) number of escape attempts and iii) total time spent on escape attempts (total time in seconds taken by each fish escaping since the first to the last escape attempts). Without any change in light conditions subsection 2.6). Individuals presenting a high latency to escape, low number of escape attempts and shorter total time escaping were characterized by a low score and identified as reactive fish. On opposite, individuals presenting a lower latency to escape, high number of escape attempts and longer total time escaping were characterized by a high score and identified as proactive (based on Castanheira et al., 2013a,b). No threshold was applied to separate subjectively the fish in two categories i.e. proactive and reactive. These data (PC1) were used as a continuous variable. Experimental groups were kept in plastic tanks (100L) during 8 months and submitted to two series of behavioural tests 14 days apart, previously described. After this period (run 3 of restraining test) individuals were randomize in three groups, housed in fibreglass stock tanks (500L) and on-grown until adult stage. Runs 1, 2 and 3 were done before and 4, 5 and 6 after sexual maturation. Details of behavioural test and sampling time points (runs) are given in the Table 1. 


\subsection{Blood sampling and cortisol analysis}

215 Blood samples were collected 30 minutes after the start of the net restraining test, according

216 to Arends et al. (1999). Therefore, fish were quickly taken out from each tank at the same time and anaesthetized with 2-phenoxyethanol (1000ppm, Sigma-Aldrich).Using heparinised syringes blood was withdrawn within $5 \mathrm{~min}$ from the caudal vein to avoid cortisol increase due to manipulation during sampling (Rotland and Tort, 1997). After sampling, blood was centrifuged at $2000 \times \mathrm{xg}$ for 20 minutes at room temperature, frozen in liquid nitrogen and stored at $-80^{\circ} \mathrm{C}$ for posterior cortisol analysis.

Plasma cortisol levels were determined using a commercial available ELISA kit (RE52611, IBL International, Hamburg), with a sensitivity of $0.05 \mathrm{ng} \mathrm{ml}^{-1}$ and precision intra- and inter-assay coefficients of variation (CV) of 7.5 and $17 \%$, respectively. This kit has been previously validated for seabream (López-Olmeda et al. 2009).

\subsection{Sperm quality analyses}

Thirty minutes after the restraining test sperm was collected by stripping ( $\mathrm{n}=39$ males). For this the anesthetized fish were placed on a holderwith the belly facing up, and gentle pressure was applied from each side of the belly toward the genital pore while sperm were collected using a syringe without needle., After collection sperm was maintained at $4{ }^{\circ} \mathrm{C}$ for motility analyses. Sperm motility was analysed in duplicate using a computer-assisted sperm analysis (CASA) software. The CASA software integrates the successive positions of the heads of moving spermatozoa in consecutive frames of video records to calculate their trajectories and characteristics. Sperm placed in a Makler chamber $(0.5 \mu$ l of diluted sperm; $1: 6, v / v$ in $1 \% \mathrm{NaCl})$ was activated with $20 \mu$ of sea water, and immediately, digitalized images obtained using 10x negative phase contrast objective in a light microscope (Nikon E200, Tokyo, Japan) were recorded with a Basler camera (Basler Afc, Ahrensburg, Germany) at 15, 30, 45 and 60 seconds post-activation. Images were processed with CASA software to determine total spermatozoa 
motility, which refers to the fraction of sperm that display any type of movement (TM, \%),

241 progressive motility, fraction of sperm moving in a straight line (PM, \%), curvilinear velocity,

242 the actual velocity along the trajectory $(\mathrm{VCL}, \mathrm{m} / \mathrm{s})$,straight line velocities, the straight line distance between the start and the end points of the track divided by the time of the trace

244 (VSL, $\mathrm{m} / \mathrm{s}$ ) and linearity index, the ratio of the net distance moved to total path distance(LIN, $\%)$.

\subsection{Data and Statistical analysis}

All statistical analyses were performed in SPSS 19.0 for Windows (IBM, USA). The results are presented as mean \pm standard deviation (SD). Behaviours measured in the net restraining test (i.e. latency to escape, number of escape attempts and total time spent on escape attempts) were collapsed into first principal component scores (PC1) using Principal Components Analysis (PCA), with orthogonal rotation (varimax). The correlation matrix was used to check multicollinearity, i.e., to identify variables that did not correlate with any other variable, or correlate very highly $(r=0.9)$ with one or more other variables. Kaiser-Meyer-Olkin (KMO) test for sample adequacy was greater than 0.5 and Bartlett's test of sphericity was significant, indicating that correlation between items was sufficiently robust for PCA. Spearman correlation analyses were used when data failed to pass the normality KolmogorovSmirnov test. A two-step cluster analyses was performed using the PC1 net restraining. $\mathrm{p}<0.05$. 


\section{Results}

\subsection{Coping styles plasticity: Short and long-term consistency}

The PCA loadings of the net restraining test variables used to generate the principal component score (PC1) to assess consistency over time between runs are shown in Table. 2. There was a significant correlation between the escape behaviour in runs 1 and 2 (14 days apart) of the restraining test Figure. $1\left(r_{s}=0.354, p=0.009\right)$. The escape response during the restraining test was shown to be repeatable over a period of 14 days: individuals showing lower latency to escape, higher number of escape attempts and spending more time escaping in run 1 showed a similar behaviour after 14 days when the test was repeated to check shortterm consistency. In addition, a long-term consistency run3 (8 months after run1) was also observed. Figure 2 shows a significant correlation between the escape behaviour in runs 1 and $3\left(r_{s}=0.286, p=0.036\right)$, runs 2 and $3\left(r_{s}=0.675, p<0.001\right)$ of the restraining test. No consistency could be found in run 4 (16 months, $r_{s}=0.147, p=0.302$ ); run 5 ( 22 months $r_{s}=-0.211, p=0.146$ ) and run 6 (39 months, $\left.r_{s}=-0.243, p=0.092\right)$ in relation to run1, or run 4 (16 months, $r_{s}=0.270$, $p=0.062$ ); run 5 (22 months $\left.r_{s}=-0.168, p=0.249\right)$ and run 6 (39 months, $\left.r_{s}=-0.095, p=0.515\right)$ in relation to run2, or run 4 (16 months, $r_{s}=0.302, p=0.031$ ); run 5 ( 22 months $r_{s}=-0.118, p=0.418$ ) and run 6 (39 months, $\left.r_{s}=-0.097, p=0.506\right)$ in relation to run3, or between run 4 and $5\left(r_{s}=-\right.$ $0.032, p=0.826)$ and runs 4 and $6\left(r_{s}=-0.118, p=0.419\right)$ or 5 and $6\left(r_{s}=0.220, p=0.129\right)$.

284

\subsection{Plasma cortisol concentrations after restraining test}

Figure 3 depicts the post-stress cortisol levels over time, $F(3,199)=387.146, p<0.001$, with a mean rank of 44.62 for run $1,47.89$ for run 2, 294.69 for run 5 and 443.91 for run 6 . Plasma cortisol was not significantly correlated with the escape behaviour during the restraining test run1 $\left(r_{s}=-0.207, p=0.133\right)$, run2 $\left(r_{s}=0.012, p=0.933\right)$, run5 $\left(r_{s}=0.220, p=0.129\right)$ and run6 $\left(r_{s}=0.136, p=0.350\right)$. 


\subsection{Relationship between sperm motility and coping styles}

Motility sperm parameters decreased linearly from 15 to 60 seconds post-activation. No significant differences were found in sperm motility related with the behavioural responses during run 6 of the restraining $p>0.05$.

\section{Discussion}

The main objective of the current study was to characterize fish coping styles considering the consistency of behavioural responses over time and during life history using the behavioural responses during a net restraining test and cortisol responsiveness at distinct life history stages. This study showed consistency in behavioural responses (over time) during the restraining test until 8 months after the first screening. More specifically, individual escape response in run 1 was similar to the escape response observed after 14 days (short-term consistency) and 8 months (long term-consistency) when the test was repeated. However, in the runs after (run 3) the onset of sexual maturation this escape behaviour consistency during restraining was lost. In our study, the short-time consistency met complies with previous studies indicating the presence of coping styles that seemed based on innate traits (Brelin et al. 2005; Castanheira et al. 2013; Huntingford 1976; Martins et al. 2012; Millot et al. 2014; $\varnothing$ verli et al. 2004) and don't add any novelity to the previous findings in fish coping styles. However, the lack of consistency found in coping styles along life stages is a new important finding. These results are expected and suggest that differences in coping styles expressed at early developmental stages may change according age and life history experiences. Highlighting that coping styles are not fixed and this can be reflected in distinct behavioural strategies to cope with the same stressful condition Thus, different life stages could mean a paradigm shift in coping styles field and following hypotheses may be considered to contribute to this lack of consistency in escape behaviour responses: (1) the sexual maturation and the sex inversion process compromise the consistency of coping styles abilities or/and (2) the 
contextual importance of the net restraining response may differ according to age and fish development.

320 Sex has been identified as a factor influencing coping strategies in fish ( $\varnothing$ verli et al. 2006; Reyes-Tomassini 2009). In fact, Øverli et al. (2006) demonstrated sex-specific variations in behavioural responses to an acute confinement stress in rainbow trout, with females decreasing and stopping to move faster than males. In addition, Reyes-Tomassini (2009) established that proactive individuals play a role in seabream sex change, but to ascertain their exact influence needs more accurate investigation in order to predict a model of that contribution. The coping styles screening using the behaviour of the net restraining test in run 4 of our experiment was done in fish sexual mature (i.e. all fish were males with active sperm production) however, in run 5 the screening were done in other stage of fish life (i.e. after sex inversion) this mean that some of the fish that we have screening before now are females. Taking the previous studies into account, we can hypothesise that males and females will behave differently when confronted with the same challenge (i.e. net restraining) and sex maturation and sex inversion processes could have played a role on the results found in this work (i.e. the absence of behaviour consistency in the net restraining test found after sex reversion). However, very little is known about the influence of sex change on the coping strategies of fish species that experience sex inversion.

In contrast, it is well known that changes of context may induce divergent behaviour responses in fish with distinct coping styles. In Artic charr, Magnhagen et al. (2015) found a lack of consistency in behavioural responses (i.e. per cent time struggling) between two runs related with the different experiences which fish were subjected before the runs. The first run was performed with fish immediately taken from their home tank, but the second run was preceded by a feeding and a resident-intruder test. Similarly, in our study the run 3 and 342 following runs were performed with fish immediately taken from their home tank, however the first to runs were preceded by feeding observation and a novel object test, giving another 
experience to the individuals compared to the last runs. Hence, the results found may be also a

345 reflection of contextual changes. Similarly, Frost et al. (2007) found that positive and negative

346 life events can predict changes in personality in rainbow trout. Once the individual internalizes those experiences they are said to be a part of that individual personality. In addition, individuals also receive feedback from other individuals or groups about their own personality and this can be a driving force of change in personality in our study. Moreover, our previous results suggest that social context affect stability of coping styles for gilthead seabream before sexual maturation (Castanheira et al. 2016). Thus, individual experiences vary as a function of age, social context and major life events (e.g. sex maturation and sex inversion) and can lead to changes in personality. In the present study the change in response to the restraining test (escape response from the net) after sexual maturation (run3) may reflect a plasticity of coping styles. This change in coping styles of individual fish could be associated with species adaptation/survival strategies and concomitant modulation of fish physiology. While juveniles allocate almost of the energy in survival (e.g. foraging, escape), allocation of energy in adults is more focused in the reproductive success and offspring viability. The biological significance of this observation remains unclear, but it should be noted that can be related with the allostatic ability to respond to challenges.

In addition, no relationship was found between escape behaviour and plasma cortisol levels. Several studies have documented the lack of correlation between plasma cortisol levels obtained after stress and behavioural responses (Silva et al. 2010; van Erp-van der Kooij et al. 2003; van de Nieuwegiessen et al. 2008). Some authors have suggested that cortisol and behavioural responses to stressors are linked to two independent dimensions of stable trait characteristics (Koolhaas et al. 2010). These authors suggested that the quality of the response

367 to a challenging condition (coping style) is independent from the quantity of that response 368 (stress reactivity). According to the same authors, the physiological responses to stress such as the $\mathrm{HPI}$ axis reactivity (one of the most significant differences between proactive and reactive 
individuals) is more related to an emotional response to stress than to coping styles. Eventually

371 a decoupling of these axis, coping styles and emotional, could bring new light to understand the pronounced individual variation in plasma cortisol response observed in seabream after stress. However, in this study we observed a significant increase in the magnitude of the cortisol response, more than fourfold, from juveniles to adults. This difference maybe related with the developmental stage of the fish that can affect its responsiveness to a stressor (Barton 2002). However our results are in contrast with previous studies such as Pottinger et al. (1995) who found a reduction of stress response in adult rainbow trout as a result of a reduced regulatory feedback with the onset of maturity. The possible influence of age on the stress responsiveness in seabream remains to be investigated. Such discrepancy of results may be due to species-specific behaviour and/or age influence. An alternative explanation could be that the cortisol responses found as a response of repeated stressors (i.e. at adult stage fish exhibit a cumulative response of repeated net restraining tests). Several studies demonstrate that fish can exhibit a cumulative response to repeated stressors (Carmichael et al. 1983; Flos et al. 1988; Maule et al. 1988) found that when juvenile chinook salmon were given multiple handling stressors, the peak cortisol responses after the final disturbance were cumulative.

Based on our results we could wonder whether the cortisol levels measured do in fact represent the immediate response to stressful conditions or are instead the reflection of other factors such as, genetic factors, developmental factors, environmental factors and repeated stressors that mask the correlation between behaviour and cortisol responses. An alternative explanation is that cortisol levels were measured in the peak of cortisol level for seabream (i.e. 30 min after the net restraining test). Recent evidence suggests a correlation between cortisol and behavioural responses during the recovery from stress over time and not is one specific time point (Tudorache et al. 2013, 2014). According to this, the absence of correlation found can be a reflection of using a static point of cortisol measure since a time 
dependent parameters from peak to baseline. In what refers to the results in sperm motility, no significant differences were found related with the net behavioural responses. In aquaculture, the relation between stress and reproduction (e.g. sperm motility) has been largely studied (Cosson et al. 2008; Schreck 2010). Stressful life events may have negative effects in semen quality and reproductive processes (Schreck 2010). Also, in many cases, a correlation between sperm motility and the ability to fertilize eggs has been established. However, less attention has been given to the possible correlation between fish stress coping styles and reproductive performance and/or gamete quality. The few studies found in relation to this thematic have distinct results. Clement et al $(2005 a, b)$ found that dominant African cichlid fish (Astatotilapia burtoni) are more successful breeders. In accordance with our study, Ibarra-Zatarain et al (2013), did not found significant responses between coping styles and gamete quality in Senegalese sole (Solea senegalensis). Further research is needed in order to confirm or reject the existence of a relationship between coping styles and reproductive success. This would be important to improve both broodstock husbandry and the design of aquaculture breeding programs.

\section{Conclusions}

In summary this study provides the first evidence of life history impact in the assessment of coping styles consistency. This study showed behaviour consistency responses in fish during a net restraining test only before sexual maturation. Therefore, these finding emphasize the value of taking a life history approach into account to improve knowledge in the consistency of coping styles. This suggests that behavioural aspect of coping styles are not fixed and may change according life history events. This reflects an adaptive response to physiological, behavioural and social differences along life. 
420 Besides the fundamental knowledge generate from our study, we expect that our results will

421 contribute to underline the needs to adapt aquaculture rearing strategies according different

422 individuals life history stages to improve fish welfare.

423

424 Acknowledgments

425 This publication has been supported by the European Commission under the 7th Framework

426 Programme FP7-KBBE-2010-4 Contract no.: 265957 COPEWELL. MFC benefited from funding

427 by grant SFRH/BD/94909/2013 from “Fundação para a Ciência e Tecnologia” (Portugal). The

428 authors are very grateful to João Reis and Miguel Viegas for their technical assistance.

429

430

431

432

433

434

435

436

437

438

439

440

441

442

443

444

445 
Arends, R. J., Mancera, J. M., Munoz, J. L., Wendelaar Bonga, S. E. Flik, G. 1999. The stress response of the gilthead sea bream (Sparus aurata L.) to air exposure and confinement. Journal of Endocrinology, 163, 149-157.

Barton, B. A., Schreck, C. B. Sigismondi, L. A. 1986. Multiple acute disturbances evoke cumulative physiological stress responses in juvenile Chinook Salmon. Transactions of the American Fisheries Society, 115, 245-251.

Barton, B. 2002. Stress in fishes: a diversity of responses with particular reference to changes in circulating corticosteroids. Integrative and Comparative Biology, 42, 517-525.

Basic, D., Winberg, S., Schjolden, J., Krogdahl, A. Höglund, E. 2012. Context-dependent responses to novelty in Rainbow trout (Oncorhynchus mykiss), selected for high and low poststress cortisol responsiveness. Physiology and Behaviour, 105: 1175- 1181.

Biro, P.A., Abrahams, M.V., Post, J.R., Parkinson, E.A.b 2004. Predators select against high growth rates and risk-taking behaviour in domestic trout populations._Proceedings of the Royal Society B: Biological Sciences, 271, 2233-2237.

Biro, P.A., Abrahams, M.V., Post, J.R., Parkinson, E.A. 2006. Behavioural trade-offs between growth and mortality explain evolution of submaximal growth rates. Journal of Animal Ecology, 75, 1165-1171.

Biro, P. A. \& Stamps, J. A. 2008. Are animal personality traits linked to life history productivity? Trends in Ecology and Evolution 23, 361-368.

Brelin, D., Petersson, E. Winberg, S. 2005. Divergent stress coping styles in juvenile Brown Trout (Salmo trutta). Annals of the New York Academy of Sciences, 1040, 239-245.

Brusléa-Sicard, S., Fourcault, B. 1997. Recognition of sex-inverting protandric Sparus aurata: ultrastructural aspects. Journal of Fish Biology, 50, 1094-1103.

Carmichael, G. J., Wedemeyer, G. A., McCraren, J. P. Millard, J. L. 1983. Physiological effects of handling and hauling stress on Smallmouth Bass. The Progressive Fish-Culturist, 45, 110-113.

Castanheira, M. F., Herrera, M., Costas, B., Conceição, L. E. C. Martins, C. I. M. 2013a. Can we predict personality in fish? Searching for consistency over time and across contexts. PLOS ONE, 8, e62037.

Castanheira, M. F., Herrera, M., Costas, B., Conceição, L. E. C. Martins, C. I. M. 2013a. Linking cortisol responsiveness and aggressive behaviour in gilthead seabream Sparus aurata: Indication of divergent coping styles. Applied Animal Behaviour Science, 143, 75-8

Castanheira, M.F.,Cerqueira, Marco, Millot, Sandie, Gonçalves, Rui A., Oliveira, Catarina, Conceição, L.E.C., Martins, C.I.M. (2016) ) Are personality traits consistent in fish? - The influence of social context. Applied Animal Behaviour Science.

Clement, T. S., Parikh, V., Schrumpf, M. Fernald, R. D. 2005a. Behavioral coping strategies in a cichlid fish: the role of social status and acute stress response in direct and displaced aggression. Hormones and Behavior, 47, 336-342. 
Clement, T. S., Grens, K. E. Fernald, R. D. 2005b. Female affiliative preference depends on reproductive state in the African cichlid fish, Astatotilapia burtoni. Behavioral Ecology, 16, 8388.

Coppens, C. M., De Boer, S. F. Koolhaas, J. M. 2010. Coping styles and behavioural flexibility: Towards underlying mechanisms. Philosophical Transactions of the Royal Society B: Biological Sciences, 365, 4021-4028.

Cosson, C., Groison, A.-L., Suquet, M., Fauvel, C., Dreanno, C., Billard, R. Studying sperm motility in marine fish: an overview on the state of the art. Journal of Applied Ichthyology, 24, 460-486.

Fevolden, S. E., Refstie, T. Røed, K. H. 1992. Disease resistance in rainbow trout (Oncorhynchus mykiss) selected for stress response. Aquaculture, 104, 19-29.

Fevolden, S. E., Nordmo, R., Refstie, T. Røed, K. H. 1993. Disease resistance in Atlantic salmon (Salmo salar) selected for high or low responses to stress. Aquaculture, 109, 215-224.

Flos, R., Reig, L., Torres, P. Tort, L. 1988. Primary and secondary stress responses to grading and hauling in rainbow trout, Salmo gairdneri. Aquaculture, 71, 99-106.

Francis, R. C. 1990. Temperament in a Fish: A longitudinal study of the development of individual differences in aggression and social rank in the Midas Cichlid. Ethology, 86, 311-325.

Frost, A. J., Winrow-Giffen, A., Ashley, P. J. Sneddon, L. U. 2007. Plasticity in animal personality traits: does prior experience alter the degree of boldness? Proceedings of the Royal Society B: Biological Sciences, 274, 333-339.

Gosling, S. D. 2001. From mice to men: what can we learn about personality from animal research? Psychological Bulletin, 127, 45-86.

Huntingford, F. A. 1976. The relationship between anti-predator behaviour and aggression among conspecifics in the three-spined stickleback, Gasterosteus Aculeatus. Animal Behaviour, $24,245-260$.

Huntingford, F. A., Adams, C. 2005. Behavioural syndromes in farmed fish: implications for production and welfare. Behaviour, 142, 1213-1227.

Huntingford, F. A., Adams, C., Braithwaite, V. A., Kadri, S., Pottinger, T. G., Sandøe, P. Turnbull, J. F. 2006. Current issues in fish welfare. Journal of Fish Biology, 68, 332-372.

Huntingford F.A., Andrew G., Mackenzie S., Morera D., Coyle S.M., Pilarczyk M. and Kadri S. (2010) Coping strategies in a strongly schooling fish, the common carp Cyprinus carpio. Journal of Fish Biology 76: 1576-1591.

Ibarra-Zatarain Z., Fatsini E., Rey Planellas S., Cherenguini O., Rasines I., Neil D. 2013. Preliminary results on the influence of stress coping styles on spawning success in Senegalese sole (Solea senegalensis) broodstock held in captivity, Conference paper, September 2013, $4^{\text {th }}$ Workshop on the Biology of Fish Gametes, Faro, Algarve, Portugal.

Kittilsen, S., Johansen, I. B., Braastad, B. O. Øverli, O. 2012. Pigments, parasites and personalitiy: Towards a unifying role for steroid hormones? PLOS ONE, 7, e34281. 
Koolhaas, J. M., Korte, S. M., De Boer, S. F., Van Der Vegt, B. J., Van Reenen, C. G., Hopster, H., 549 De Jong, I. C., Ruis, M. A. W. Blokhuis, H. J. 1999. Coping styles in animals: current in behavior 550 and stress-physiology. Neuroscience and Biobehavioral Reviews, 23, 925-935. Korte, S. M., J.M., K., J.C., W. B.S., M. 2005. The Darwinian concept of stress: Benefits of allostasis and costs of allostatic load and the trade-offs in health and disease. Neuroscience and Biobehavioral Reviews, 29, 3-38.

López-Olmeda, J. F., Montoya, A., Oliveira, C. Sánchez-Vázquez, F. J. 2009. Synchronization to light and restricted-feeding schedules of behavioral and humoral daily rhythms in gilthead sea bream (Sparus aurata). Chronobiology International, 26, 1389-1408.

MacKenzie, S., Ribas, L., Pilarczyk, M., Capdevila, D. M., Kadri, S. Huntingford, F. A. 2009. Screening for coping style increases the power of gene expression Studies. PLOS ONE, 4, e5314.

Magnhagen, C., Backström, T., Øverli, Ø., Winberg, S., Nilsson, J., Vindas, M. A. Brännäs, E. 2015. Behavioural responses in a net restraint test predict interrenal reactivity in Arctic charr Salvelinus alpinus. Journal of Fish Biology, 87, 88-99.

Martins, C. I. M., Conceição, L. E. C. Schrama, J. W. 2011. Consistency of individual variation in feeding behaviour and its relationship with performance traits in Nile tilapia Oreochromis niloticus. Applied Animal Behaviour Science, 133, 109-116.

Martins, C. I. M., Schaedelin, F. C., Mann, M., Blum, C., Mandl, I., Urban, D., Grill, J., Sch, wender, J. Wagner, R. H. 2012. Exploring novelty: a component trait of behavioural syndromes in a colonial fish. Behaviour, 149, 215-231.

Maule, A. G., Schreck, C. B., Bradford, C. S. Barton, B. A. 1988. Physiological effects of collecting and transporting emigrating juvenile Chinook Salmon past dams on the Columbia river. Transactions of the American Fisheries Society, 117, 245-261.

McCarthy, I.D. 2001. Competitive ability is related to metabolic asymmetry in juvenile rainbow trout Journal of Fish Biology 59, 1002-1014.

Metcalfe, N. B. 1998. The interaction between behavior and physiology in determining life history patterns in Atlantic salmon (Salmo salar)Canadian Journal of Fisheries and Aquatic Sciences 55, 93-104.

Millot, S., Cerqueira, M., Castanheira, M.-F., Øverli, Ø., Oliveira, R. F. Martins, C. I. M. 2014. Behavioural Stress Responses Predict Environmental Perception in European Sea Bass (Dicentrarchus labrax). PLOS ONE, 9, e108800.

Millot S., Bégout M.L., Chatain B. (2009) Risk-taking behaviour variation over time in sea bass Dicentrarchus labrax: effects of day-night alterations, fish phenotypic characteristics and selection for growth. Journal of Fish Biology 75: 1733-174

Morales, J. C. 1983. Acuicultura marina animal, ed. Mundi-Prensa, Madri. 1.423p.

$\varnothing$ verli, Ø., Korzan, W. J., Höglund, E., Winberg, S., Bollig, H., Watt, M., Forster, G. L., Barton, B. A., $\varnothing$ verli, E., Renner, K. J. Summersa, C. H. 2004a. Stress coping style predicts aggression and social dominance in rainbow trout. Hormones and Behavior 45, 235- 241. 

Summersa, C. H. 2004b. Behavioral and neuroendocrine correlates of displaced aggression in trout. Hormones and Behavior 45, 324- 329.

$\varnothing$ verli, $\varnothing$., Sørensen, C. Nilsson, G. E. 2006. Behavioral indicators of stress-coping style in rainbow trout: Do males and females react differently to novelty? Physiology \& Behavior, 87, 506-512.

$\varnothing$ verli, $\varnothing$., Sørensen, C., Pulman, K. G. T., Pottinger, T. G., Korzan, W., Summers, C. H. Nilsson, G. E. 2007. Evolutionary background for stress-coping styles: Relationships between physiological, behavioral, and cognitive traits in non-mammalian vertebrates. Neuroscience and Biobehavioral Reviews, 31, 396-412.

Pottinger, T. G., Balm, P. H. Pickering, A. D. 1995. Sexual maturity modifies the responsiveness of the pituitary-interrenal axis to stress in male rainbow trout. General and Comparative Endocrinology, 98, 311-320.

Réale, D., Reader, S. M., Sol, D., McDougall, P. T. Dingemanse, N. J. 2007. Integrating animal temperament within ecology and evolution. Biological Reviews of the Cambridge Philosophical Society, 82, 291-318.

Reyes-Tomassini, J. J. 2009. Behavioral and neuroendocrine correlates of sex change in the Gilthead Seabream Sparus aurata (PhD Thesis) Faculty of the Graduate School of the University of Maryland, College Park,USA.

Rotllant, J.Tort, L. 1997. Cortisol and glucose responses after acute stress by net handling in the sparid red porgy previously subjected to crowding stress. Journal of Fish Biology, 51, 21-28.

Ruiz-Gomez, M.L., Huntingford, F. A., Øverli, Ø., Thörnqvist, P.-O. Höglund, E. 2011. Response to environmental change in rainbow trout selected for divergent stress coping styles. Physiology \& Behavior,102, 317-322.

Schjolden, J., Winberg, S. 2007. Genetically determined variation in stress responsiveness in rainbow trout: behavior and neurobiology. Brain Behav Evol, 70, 227-238.

Schreck, C. B. 2010. Stress and fish reproduction: The roles of allostasis and hormesis. General and Comparative Endocrinology, 165, 549-556.

Seebacher, F., Little, A.G., James, R.S. 2015. Skeletal muscle contractile function predicts activity and behaviour in zebrafish. Journal of Experimental Biology 218, 3878-3884.

Sih, A., Bell, A. Johnson, J. C. 2004. Behavioral syndromes: an ecological and evolutionary overview. Trends in Ecology \& Evolution, 19, 372-378.

Silva, P. I. M., Martins, C. I. M., Engrola, S., Marino, G., Øverli, Ø. Conceição, L. E. C. 2010. Individual differences in cortisol levels and behaviour of Senegalese sole (Solea senegalensis) juveniles: Evidence for coping styles. Applied Animal Behaviour Science, 124, 75-81.

Tudorache, C., Schaaf, M.J.M., Slabbekoorn, H. 2013. Endocrine stress response varies with coping style in zebrafish. Journal of Endocrinology 219, 251-258. 
Tudorache, C., ter Braake, A., Tromp, M., Slabbekoorn, H., Schaaf, M.J.M. 2015.Behavioral and physiological indicators of stress coping styles in larval zebrafish. Stress 18, 121-128.

653

662

663

664

665

666

667

668

669

670

671

672

673

674

675

676

677

678

679

680

681

van Erp-van der Kooij, E., Kuijpers, A. H., van Eerdenburg, F. J. C. M., Dieleman, S. J., Blankenstein, D. M. Tielen, M. J. M. 2003. Individual behavioural characteristics in pigsinfluences of group composition but no differences in cortisol responses. Physiology \& Behavior, 78, 479-488.

van de Nieuwegiessen, P. G., Schrama, J. W. Verreth, J. A. J. 2008. A note on alarm cues in juvenile African catfish, Clarias gariepinus Burchell: Indications for opposing behavioural strategies. Applied Animal Behaviour Science, 113, 270-275.

2

(1)

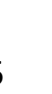

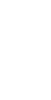

7

669

70


683

684

685

686

687

688

689

690

691

692

693

694

695

696

697

698

699

700

701

702

703

704

Table 1. Overview of analyses and sampling time points (runs) during the experiment.

Table 2. PCA loadings of the net restraining test variables used to generate a principal component scores (PC1) in runs 1, 2, 3, 4, 5 and 6.

Figure 1. Relationship between the PC1 behavioural personality score (from run1 and run2) during the net restraining test on seabream Sparus aurata $(n=60)$ - short-term consistency trial.

Figure 2. Relationship between the PC1 behavioural personality score (run1 and run3; run2 and run3 respectively for graphs on the top and bottom) during the net restraining test on seabream Sparus aurata $(n=60)$ - long term-consistency trial.

Figure 3. Cortisol post-stress responsiveness over time (run1, run2, run5 and run6) on seabream Sparus aurata juveniles $(n=60)$. Data are presented as means \pm SD. Different letters indicate significant differences (nonparametric test, Kruskal-Wallis test: $p<0.001$ ).

Figure 4. Sperm motility parameters (A-total spermatozoa motility; B-linearity index, LIN) in proactive, intermediate and reactive males at 10,20, 30 and $45 \mathrm{~s}$ post-activation. Statistical analyses were performed using general linear models with the Bonferroni correction $(p<$ $0.05)$. 
Table.1

\begin{tabular}{|c|c|c|c|c|c|c|c|}
\hline \multicolumn{3}{|c|}{ Restraining } & \multirow[b]{2}{*}{ Weight (mean \pm SD) } & \multirow[b]{2}{*}{$\mathbf{N}$} & \multirow[b]{2}{*}{$\begin{array}{c}\text { Racio } \\
\text { males:females } \\
\end{array}$} & \multirow[b]{2}{*}{ Notes } & \multirow[b]{2}{*}{ Analyses } \\
\hline Run & Date 1 & Date 2 & & & & & \\
\hline 1 & $13-09-2011$ & ------ & $(22.7 \pm 3.9 \mathrm{~g})$ & 56 & ------ & Before sexual maturation (undifferentiated gonads) & Restraining, cortisol \\
\hline 2 & 27-09-2011 & $\begin{array}{l}14 \text { days after } \\
\text { run1 }\end{array}$ & $(39.2 \pm 8.0 \mathrm{~g})$ & 56 & ------ & Before sexual maturation (undifferentiated gonads) & Restraining, cortisol \\
\hline 3 & $24-05-2012$ & $\begin{array}{c}8 \text { months after } \\
\text { run1 }\end{array}$ & $(98.9 \pm 15.3 \mathrm{~g})$ & 56 & ------ & Before sexual maturation (undifferentiated gonads) & Restraining \\
\hline 4 & $12-01-2013$ & $\begin{array}{c}16 \text { months after } \\
\text { run1 }\end{array}$ & $(454.1 \pm 69.0 \mathrm{~g})$ & 53 & 53:0 & After sexual maturation (all males produced sperm) & $\begin{array}{l}\text { Restraining, sperm } \\
\text { production }\end{array}$ \\
\hline 5 & 04-11-2013 & $\begin{array}{l}22 \text { months after } \\
\text { run1 }\end{array}$ & $(856.8 \pm 127.0 \mathrm{~g})$ & 53 & $38: 15$ & After sexual maturation sex change (38 males) & $\begin{array}{l}\text { Restraining, cortisol, } \\
\text { sperm production }\end{array}$ \\
\hline 6 & $13-12-2013$ & $\begin{array}{l}23 \text { months after } \\
\text { run1 }\end{array}$ & $(832.9 \pm 127.7 \mathrm{~g})$ & 51 & 39:14 & After sexual maturation sex change (39 males) & $\begin{array}{l}\text { Restraining, cortisol, } \\
\text { sperm production ano } \\
\text { sperm quality } \\
\text { parameters }\end{array}$ \\
\hline
\end{tabular}




\begin{tabular}{|c|c|c|c|}
\hline Behavioural test: Restraining & \multicolumn{3}{|c|}{ Behavioral variables } \\
\cline { 2 - 4 } & $\begin{array}{c}\text { Latency to } \\
\text { escape }\end{array}$ & $\begin{array}{c}\text { Number of } \\
\text { escapes }\end{array}$ & $\begin{array}{c}\text { Total } \\
\text { escaping } \\
\text { time }\end{array}$ \\
\hline Loadings for PC1- RUN 1(component matrix) & -0.809 & 0.933 & 0.877 \\
\hline \% Variation explained & \multicolumn{3}{|c|}{76.468} \\
\hline Loadings for PC1- RUN 2 (component matrix) & -0.81 & 0.868 & 0.879 \\
\hline \% Variation explained & & 72.771 \\
\hline \% Variation explained & -0.6 & 0.846 & 0.778 \\
\hline \% Variation explained & \multicolumn{3}{|c|}{} \\
\hline Loadings for PC1- RUN 4 (component matrix) & -0.554 & 0.892 & 0.856 \\
\hline \% Variation explained & \multicolumn{3}{|c|}{} \\
\hline Loadings for PC1- RUN 5 (component matrix) & -0.846 & 0.945 & 0.904 \\
\hline Loadings for PC1- RUN 6 (component matrix) & -0.838 & 0.893 & 0.857 \\
\hline & & 74.49 \\
\hline
\end{tabular}


Figure.1

710 Short-term consistency

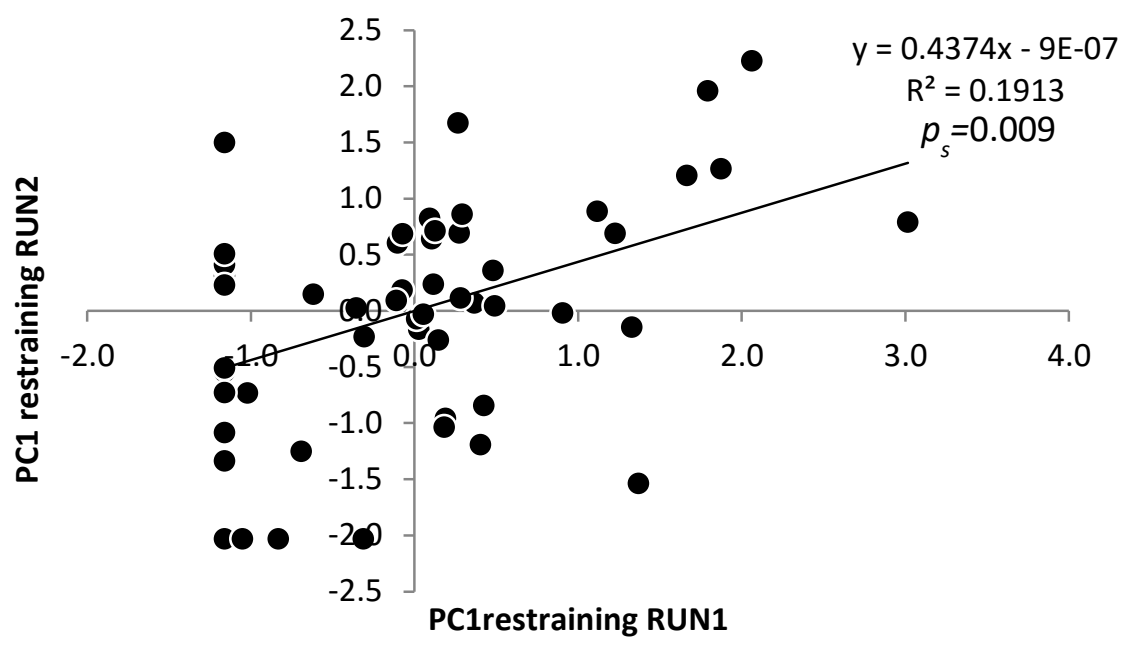

711 Figure.2

712 Long-term consistency

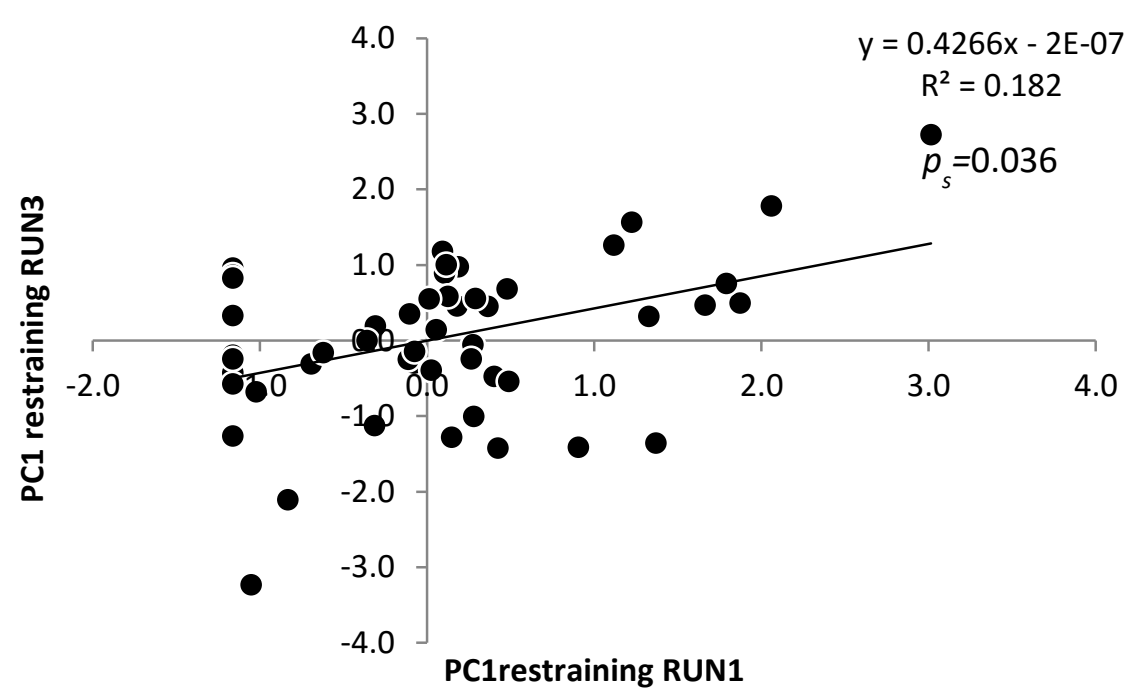




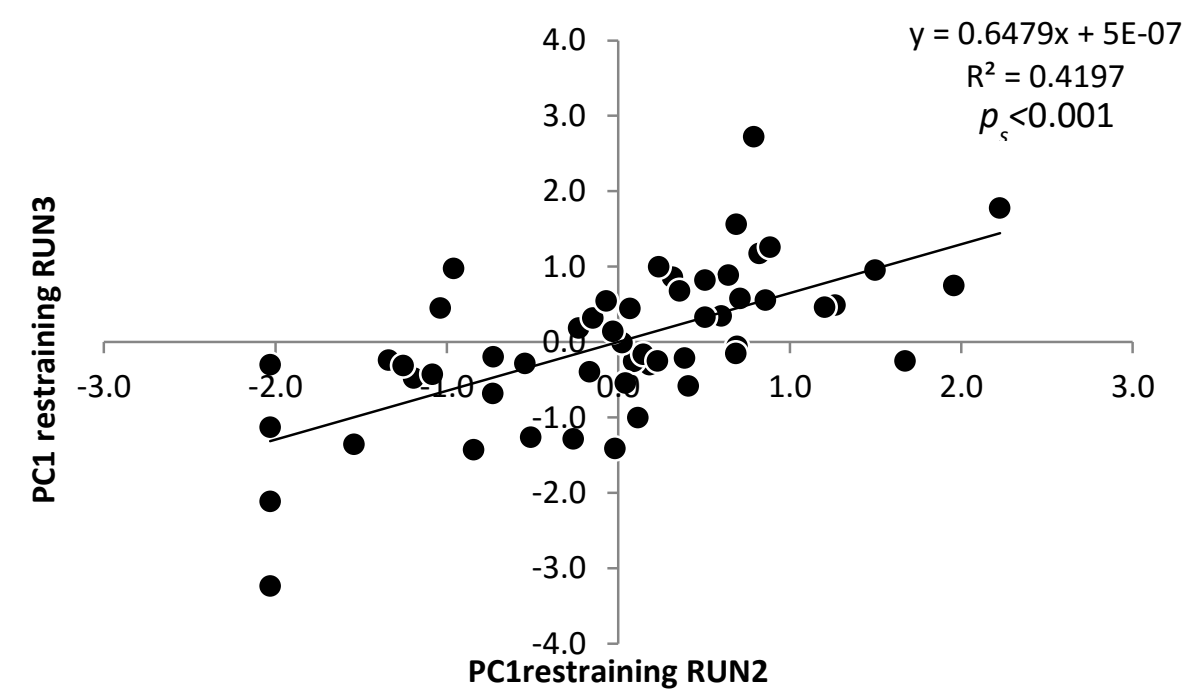

713

714

715

Figure.3

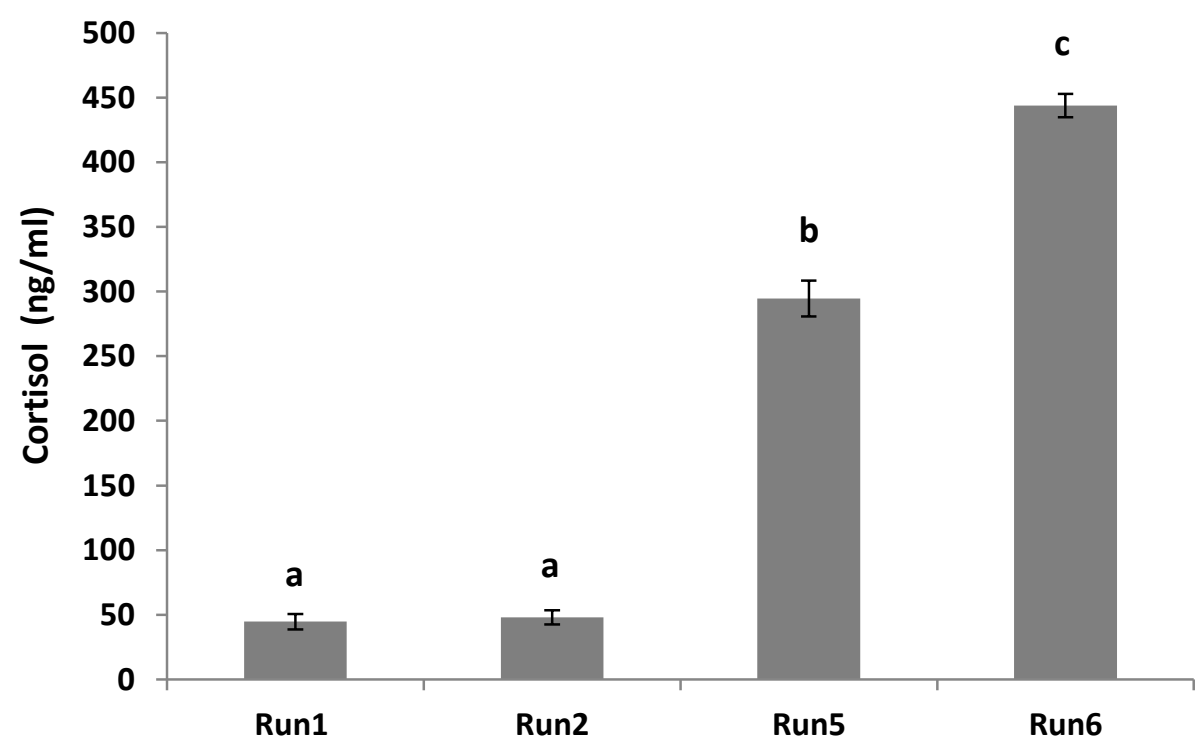

716

717

718

719

720 


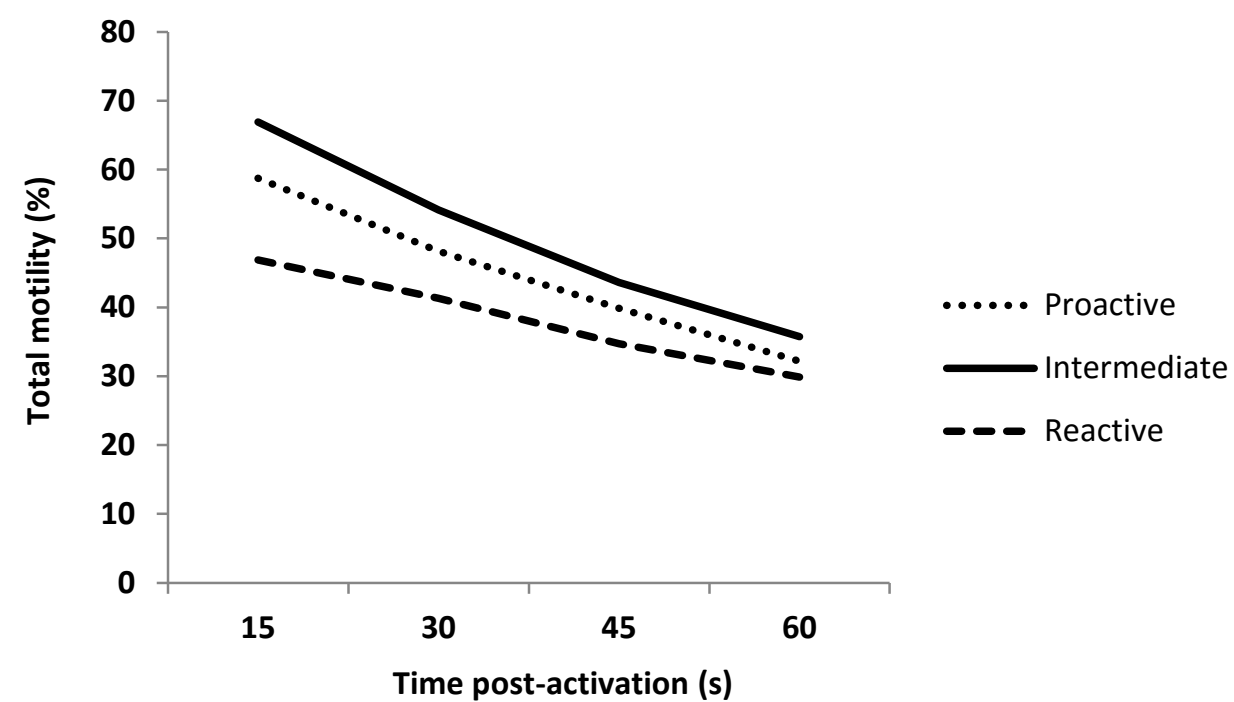

A

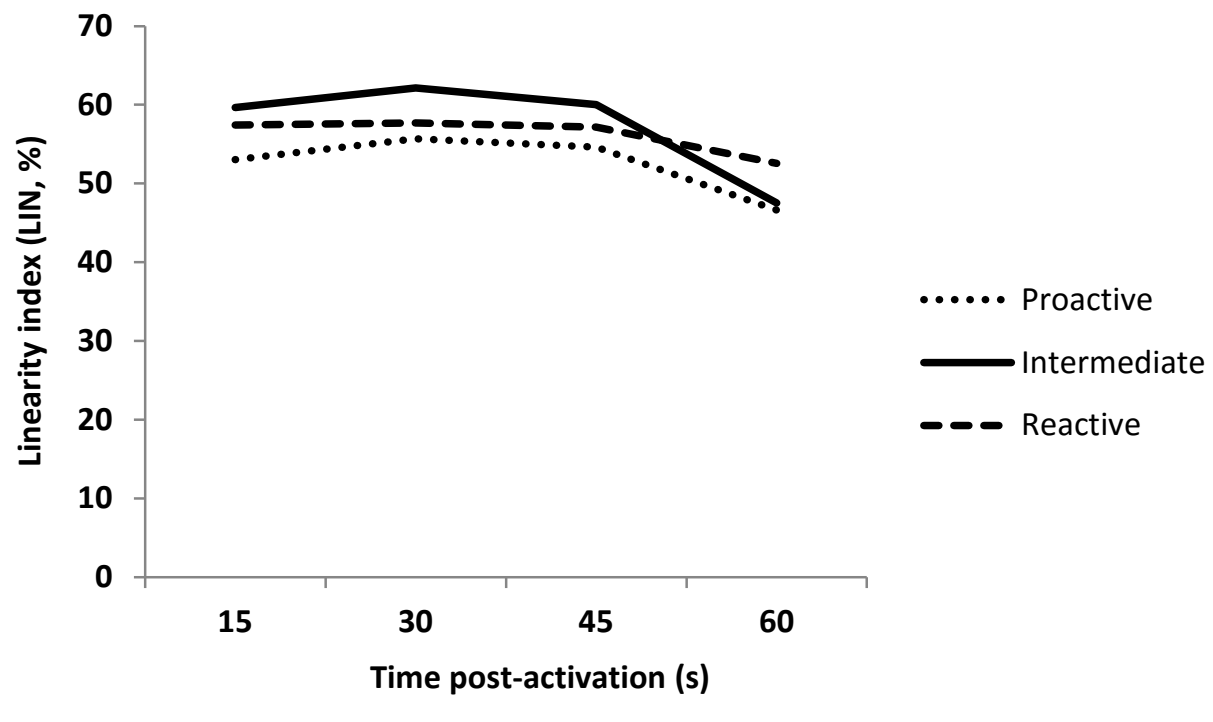

